\title{
Back analysis of drifting-snow measurements over an instrumented mountainous site
}

\author{
Florence NAAIM-BOUVET, Hervé BELLOT, Mohamed NAAIM \\ Cemagref - UR ETNA, 2 rue de la Papeterie, BP 76, 38402 Saint-Martin-d'Hères, France \\ E-mail: florence.naaim@cemagref.fr
}

\begin{abstract}
The NEMO numerical model of drifting snow, whose general outlines are presented in this paper, is based on a physical model for saltation and turbulent diffusion. The model needs a set of input parameters including fall velocity, threshold shear velocity, shear velocity, mass concentration and roughness, which are obtained from empirical formulae and wind speed measured at a given height. To better determine the required field data in an alpine context, our experimental site, Col du Lac Blanc (2700 ma.s.l.), French Alps, was first equipped with one anemometer and blowing-snow acoustic sensors, which proved not to be accurate enough for research purposes in the current state of development even though a new calibration curve was used. We therefore set up a Snow Particle Counter and we returned to the traditional, robust mechanical traps and a $10 \mathrm{~m}$ mast with six anemometers, two temperature sensors and a depth sensor to better determine friction velocity and aerodynamic roughness. Based on the studied drifting-snow events we conclude: (1) the proportionality of the aerodynamic roughness to the square of the friction velocity was confirmed, but with a varying proportionality ratio depending on the snowdrift event; (2) values of $\sigma_{\mathrm{s}} U_{\mathrm{F}}$ were relatively well approximated by empirical formulae from data originating from Antarctica, and (3) snowdrift concentration profiles obtained by Pomeroy's semi-empirical formulae for the saltation layer coupled with a theoretical approach for the diffusion layer overestimated the concentration profiles for the studied blowing-snow event.
\end{abstract}

\section{INTRODUCTION}

Wind-transported snow is a common phenomenon in cold windy areas such as mountainous and polar regions. The wind erodes snow in high-wind-speed areas and deposits it in low-wind-speed areas. The resulting snowdrifts often cause problems for infrastructure and road maintenance and contribute significantly to the loading of avalanche release area. In this context, numerical simulations of drifting snow would be very helpful. In the last few decades, progress has been made in this field. Nevertheless, for practical purposes blowing- and drifting-snow models require input parameters (e.g. friction velocity, aerodynamic roughness and blowingsnow concentration profiles) which are often obtained from empirical formulae and wind speed measured at a given height (Sundsbø, 1997; Gauer, 1998; Doorschot and others, 2001; Michaux and others, 2001). Since the topography and type of snow can be quite different from one site to another, further experimental research is needed before using these formulae. To better determine the required field data in an alpine context, blowing-snow acoustic and optical instruments, a $10 \mathrm{~m}$ mast with six anemometers, two temperature sensors and a depth sensor were set up on our experimental site at Col du Lac Blanc (2700 ma.s.I.), French Alps. Data obtained during the last several winters are presented and compared with semi-empirical formulae used in the NEMO numerical model.

\section{CONTEXT OF THE STUDY}

\subsection{Main characteristics of the NEMO numerical model}

The NEMO numerical model is based on a physical model for saltation and turbulent diffusion (Naaim and others, 1998), ignoring sublimation, which is less important at the avalanche-release area scale (Fig. 1). The saltation layer is described by its height, concentration and two turbulent friction velocities, one for the solid phase and one for the gaseous phase. The top of the saltation layer is considered as the lower boundary condition for the suspension layer. The suspension layer is described by mass and momentum conservation equations. These equations were formulated both for the solid phase and the gaseous phase. The interaction between these two phases was taken into account by an equation based on the drag force of a particle in a turbulent flow. Turbulence was modeled by the $k-\varepsilon$ model, where a turbulence reduction with increasing concentration was introduced. The exchange between the saltation layer and the snow cover was described by an erosion and deposition model. The mesh was adapted to the temporal change of the drift.

This model can briefly be described by the separate flow equations for each layer (saltation, suspension and snow cover); additional information can be found in Naaim and others (1998).

In the suspension layer

Air mass conservation:

$$
\frac{\partial \rho_{\mathrm{a}}}{\partial t}+\frac{\partial}{\partial x_{i}}\left(\rho_{\mathrm{a}} \bar{u}_{i}\right)=0
$$

Particle mass conservation:

$$
\frac{\partial \bar{C}}{\partial t}+\frac{\partial}{\partial x_{i}}\left[\bar{C} \cdot\left(\bar{u}_{i}-U_{\mathrm{F} i}\right)\right]=\frac{\partial}{\partial x_{i}}\left(\frac{\nu_{\mathrm{t}}}{\sigma_{\mathrm{s}}} \frac{\partial \bar{C}}{\partial x_{i}}\right)
$$

Momentum conservation:

$$
\begin{gathered}
\frac{\partial\left(\rho \bar{u}_{i}\right)}{\partial t}+\frac{\partial}{\partial x_{j}}\left(\rho \bar{u}_{i} \bar{u}_{j}\right)+\frac{\partial \bar{p}}{\partial x_{i}} \\
=\rho \frac{\partial}{\partial x_{j}}\left[\frac{\nu_{\mathrm{t}}}{\sigma_{\mathrm{s}}}\left(\frac{\partial \bar{u}_{i}}{\partial x_{j}}+\frac{\partial \bar{u}_{j}}{\partial x_{i}}\right)-\frac{2}{3} \frac{\partial k}{\partial x_{i}} \delta_{i j}\right]+\bar{C} \frac{\left(\rho_{\mathrm{s}}-\rho_{\mathrm{a}}\right)}{\rho_{\mathrm{s}}} g_{i}
\end{gathered}
$$




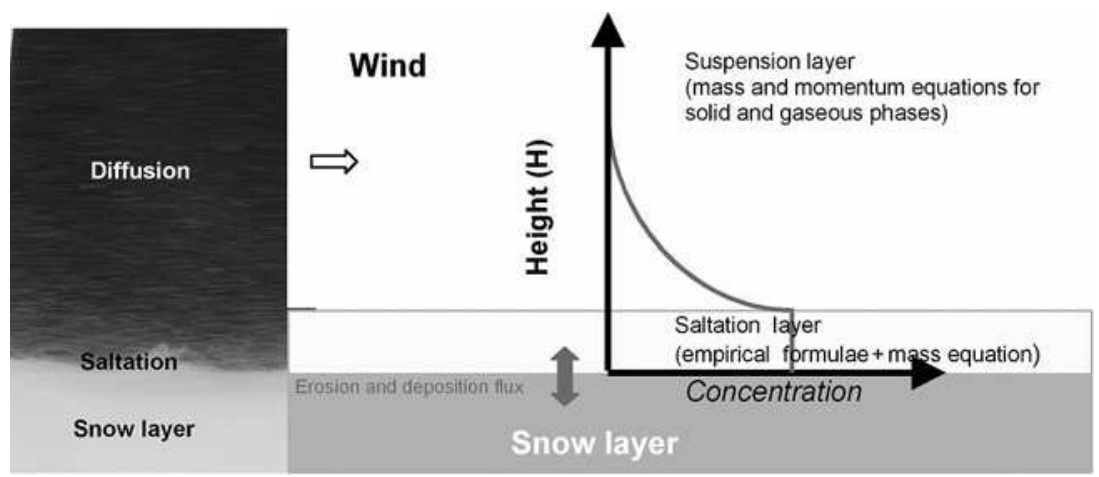

Fig. 1. Characteristics of the numerical model.

with $\rho=\rho_{\mathrm{a}}+\bar{C}\left(1-\frac{\rho_{\mathrm{a}}}{\rho_{\mathrm{s}}}\right)$. A $k-\varepsilon$ model modified by the presence of particles is used to close the system.

The solutions of the equations in a case of boundary layer over flat area for steady-state drifting snow lead to the blowing-snow mass density for a given particle radius:

$$
\frac{\bar{C}\left(x_{3}\right)}{\bar{C}\left(x_{3 \text { ref }}\right)}=\left(\frac{x_{3}}{x_{3 \text { ref }}}\right)^{-\frac{\sigma_{s}\left|u_{F}\right|}{K u_{*}}} \text {. }
$$

In the saltation layer

Particle mass conservation:

$$
\begin{gathered}
\frac{\partial \bar{C}_{\mathrm{s}}}{\partial t}+\frac{\partial\left(\bar{C}_{\mathrm{s}} \bar{u}_{\mathrm{p} i}\right)}{\partial x_{i}}=\phi_{\text {erosion }}+\phi_{\text {deposition }} \\
+\left[\frac{\partial}{\partial x_{i}}\left(\frac{\nu_{\mathrm{t}}}{\sigma_{\mathrm{s}}} \frac{\partial \bar{C}_{\mathrm{v}}}{\partial x_{i}}\right)-\left|U_{\mathrm{F}}\right| \frac{\partial \bar{C}_{\mathrm{v}}}{\partial x_{3}}\right]_{\text {at top of saltation layer }} \\
\phi_{\text {erosion }}=A\left\{\rho\left[\left(u_{* \mathrm{t}}-u_{*}\right)\left(\frac{\bar{C}_{\mathrm{s}}}{C_{\mathrm{s} \max }}\right)^{2}+u_{*}\right]^{2}-\rho u_{* \mathrm{t}}^{2}\right\} \\
\phi_{\text {deposition }}=\bar{C}_{\mathrm{s}}\left|U_{\mathrm{F}}\right| \frac{\left(u_{* \mathrm{t}}^{2}-u_{*}^{2}\right)}{u_{* \mathrm{t}}^{2}},
\end{gathered}
$$

where $\rho_{\mathrm{a}}$ is air density $\left(\mathrm{kg} \mathrm{m}^{-3}\right), \rho_{\mathrm{s}}$ is blowing-snow particles density $\left(\mathrm{kg} \mathrm{m}^{-3}\right), \bar{u}_{i}$ is the mean air velocity component in the $O_{x i}$ direction $\left(\mathrm{m} \mathrm{s}^{-1}\right)$ in the suspension layer, $\bar{u}_{\mathrm{p} i}$ is the mean particle velocity component in the $O_{x i}$ direction $\left(\mathrm{m} \mathrm{s}^{-1}\right)$ in the saltation layer, $u_{*}$ is the friction velocity $\left(\mathrm{m} \mathrm{s}^{-1}\right)$, $u_{* \mathrm{t}}$ is the threshold friction velocity $\left(\mathrm{m} \mathrm{s}^{-1}\right), x_{3}$ is the vertical component, $\bar{C}$ is the mean particle concentration in the suspension layer $\left(\mathrm{kg} \mathrm{m}^{-3}\right), \bar{C}_{\mathrm{s}}$ is particle concentration in the saltation layer $\left(\mathrm{kg} \mathrm{m}^{-3}\right), C_{\mathrm{s} \text { max }}$ is the maximum particle concentration in the saltation layer $\left(\mathrm{kg} \mathrm{m}^{-3}\right), \nu_{\mathrm{t}}$ is the turbulent viscosity coefficient $\left(\mathrm{m}^{2} \mathrm{~s}^{-1}\right), \bar{p}$ is the mean pressure $\left(\mathrm{N} \mathrm{m}^{-2}\right), g$ is gravitational acceleration $\left(\mathrm{m} \mathrm{s}^{-2}\right), \sigma_{\mathrm{s}}$ is the Schmidt number, $K$ is the von Kármán constant and $k$ is the turbulent kinetic energy $\left(\mathrm{m}^{2} \mathrm{~s}^{-2}\right)$.

\subsection{Input parameters}

The model needs a set of input parameters including fall velocity, threshold shear velocity, shear velocity, mass concentration and roughness. NEMO has been tested by comparing leeward and windward drift equilibrium obtained in a wind tunnel near a small-scale snow fence (Naaim and others, 1998) with all these input parameters known; moreover these parameters remained constant throughout the experiment. However, the computation results were often less conclusive when compared to the results of field experiments (Michaux and others, 2001) conducted at Col du Lac Blanc. It is true that the fully coupled wind and snowdrift model was not used in this case because of the time required for calculation, and that additional assumptions were made. However, it is probable that the most important source of uncertainty stems from the lack of accurate evaluations of the input parameters needed for the numerical model. In fact, at our experimental site, where NEMO was tested (Michaux and others, 2001), only wind speed and direction as well as a snowdrift sensor based on an acoustic principle could be accessed. This snowdrift sensor provided information on whether or not snowdrift events had occurred.

Thus, some parameters were estimated from semi-empirical relationships obtained with data probably collected under different conditions than those encountered in the Alps in terms of topography and snow types. Therefore, the following relationships from Pomeroy and Gray's (1990, 1993) work were used:

$$
\begin{gathered}
Q_{\mathrm{s}}=\frac{0.68 \rho u_{* \mathrm{t}}}{g u_{*}}\left(u_{*}^{2}-u_{* \mathrm{t}}^{2}\right) \\
h_{\mathrm{s}}=\frac{1.6 u_{*}^{2}}{2 g} \\
C_{\text {salt }}=\frac{\rho}{3.29 u_{*}}\left(1-\frac{u_{* \mathrm{t}}^{2}}{u_{*}^{2}}\right) \\
z_{0}^{\prime}=0.1203 \frac{u_{*}^{2}}{2 g} .
\end{gathered}
$$

$Q_{\mathrm{s}}$ is the total mass-transport rate per unit of lateral dimension in the saltation layer $\left(\mathrm{kg} \mathrm{m}^{-1} \mathrm{~s}^{-1}\right), h_{\mathrm{s}}$ is the height of the saltation layer $(\mathrm{m}), C_{\text {salt }}$ is the maximum drift density of saltating snow $\left(\mathrm{kg} \mathrm{m}^{-3}\right)$ and $z_{0}^{\prime}$ is the aerodynamic roughness $(\mathrm{m})$.

In our case, the value of $\sigma_{\mathrm{s}} U_{\mathrm{F}}$ was estimated based on the experimental dataset published by Mellor and Fellers (1986), which consisted of 1200 usable data from Mellor and Radok (1960) and Budd and others (1966) obtained by anemometers and aerodynamic snow collectors mounted in pairs on vertical masts in Antarctica. Velocity and concentration profiles were used to calculate the exponent of Equation (4) (Naaim-Bouvet and others, 1996; Fig. 2):

$$
\sigma_{\mathrm{s}} U_{\mathrm{F}}=0.38 u_{*}+0.12 \quad\left(R^{2}=0.7\right) .
$$

The increase of $\sigma_{\mathrm{s}} U_{\mathrm{F}}$ with $u_{*}$ is caused by the increase of the 


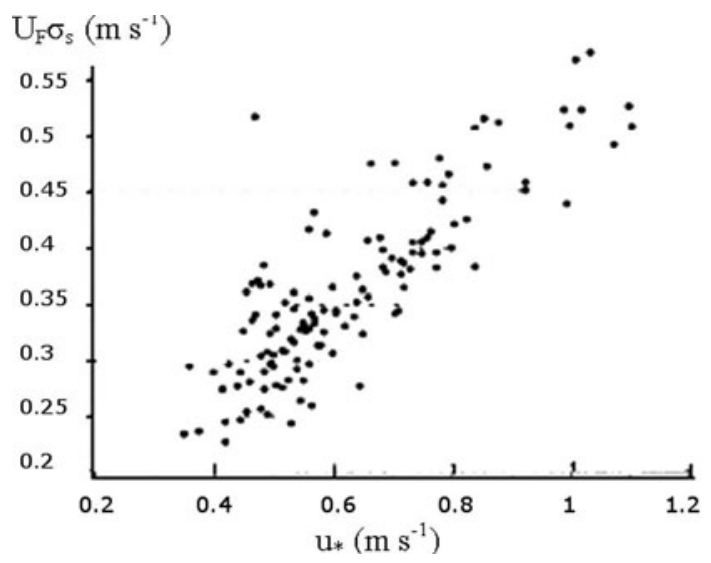

Fig. 2. Change in product $\sigma_{\mathrm{s}} U_{\mathrm{F}}$ as a function of $u_{*}$ (Naaim-Bouvet and others, 1996).

mean diameter of the wind-borne particles with increasing $u_{*}$.

Despite the approximations above, accurate evaluation of the input parameters needed for the numerical model remains an open question. Few quantitative measurements from Alpine sites are available (Doorschot and others, 2004), which is why, in the last few years, we returned to the field to improve measurements of drifting snow at Col du Lac Blanc pass by testing these empirical formulae in an alpine context.

\section{IN SITU MEASUREMENTS OF DRIFTING SNOW}

\subsection{Description of the site and the available instrumentation}

The experimental site (Naaim-Bouvet and others, 2000) is located at the Alpe d'Huez ski resort near Grenoble, France. The large north-south-oriented pass (Col du Lac Blanc) has been dedicated to the study of blowing snow in high mountainous regions for approximately 20 years. The area consists of relatively flat terrain on a length of about $300 \mathrm{~m}$. The slope then becomes steeper both in the northern and southern parts. Far away, the terrain becomes flat again and lakes occupy many depressions. In the eastern part of the site stands a high alpine range, 'Grandes Rousses', culminating at about $3500 \mathrm{~m}$ a.s.l. with Pic Bayle, whereas a lower summit (Dôme des Petites Rousses) lies on the west. The pass orientation and the specific configuration of the 'Grandes Rousses' range make the pass very close to a natural wind tunnel. North or south account for $80 \%$ of the wind directions.

In 2000, when the NEMO model was first validated at Col du Lac Blanc (Michaux and others, 2001), several parameters (air temperature, wind direction and speed, snow depth, water equivalent of precipitation) were recorded every $15 \mathrm{~min}$. This standard measurement device was supplemented by six acoustic snowdrift sensors, consisting of a miniature microphone located at the base of a $2 \mathrm{~m}$ long aluminium pole and initially designed at Cemagref and manufactured by AUTEG (Font and others, 1998; Michaux and others, 2001). The pole was exposed to the snow particle flux, and part of the flux impacted on the pole during blowing snow. The sound produced by these impacts is recorded as an electrical signal. The sensors were not calibrated, but reliably recorded the beginning and end of

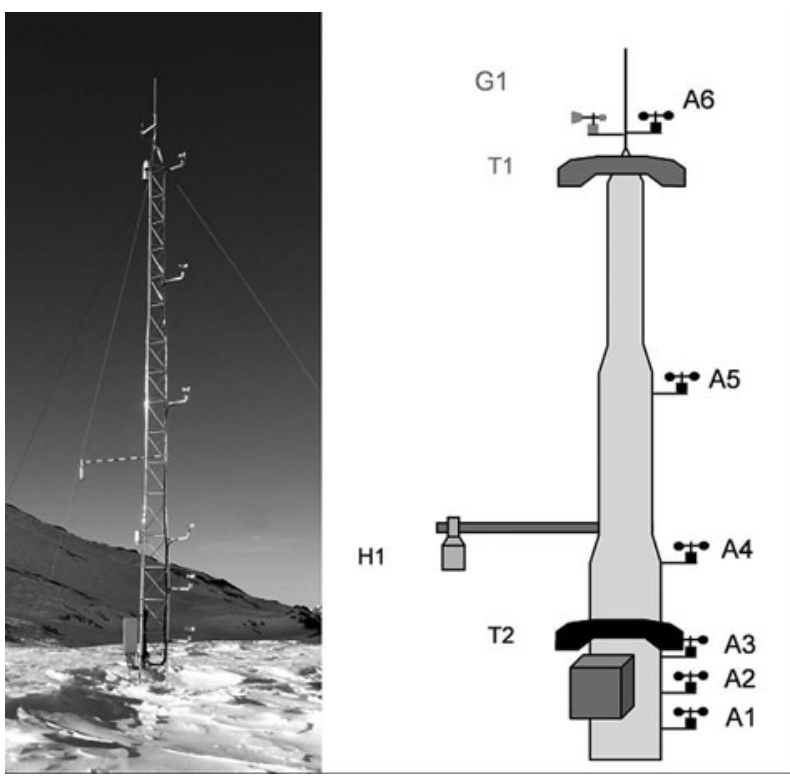

Fig. 3. A $10 \mathrm{~m}$ tower with six anemometers including snow-depth and temperature measurements.

blowing-snow events. The three-dimensional spatial distribution was investigated using a network of metallic snow poles on erosion zones as well as on accumulation zones. The instrumentation was then progressively improved and updated.

\subsubsection{Wind measurements}

In 2004, the site was fitted with an ultrasonic anemometer (Metek USA-1) set up at $3.3 \mathrm{~m}$ height. The sonic anemometer can simultaneously record each component of the wind vector at time rates up to $10 \mathrm{~Hz}$. Moreover, temperature estimation is computed from a measure of the sound celerity at the same time rate. In 2007, six cup anemometers (A1A6) were mounted on a $10 \mathrm{~m}$ vertical mast with logarithmically vertical spacing (Fig. 3). Temperatures (T1 and T2) were monitored by platinum resistance thermometers at the same place as A3 and A6, and the experimental set-up was completed by a snow depth sensor $(\mathrm{H} 1)$. The mast aims at better investigation of the friction velocity and the aerodynamic roughness.

\subsubsection{Blowing-snow measurements}

If sensors for wind measurements are reliable and accurate, this is still not the case for all blowing-snow sensors. Different techniques are available such as acoustic (Chritin and others, 1999; Michaux and others, 2001), optical (Sato and Kimura, 1993) and pulse-counting techniques (Bintanja and others, 2001). Extensive and time-consuming tests are sometimes still needed before interpreting the results quantitatively.

FlowCapt acoustic sensor. FlowCapt consists of Tefloncoated tubes fitted with electroacoustic transducers (Fig. 4). During snowdrift events, particles impact the tubes, inducing acoustical pressure inside the tubes. This is picked up by the transducers. The signal is then filtered and amplified. The device is delivered with complete calibration, which is performed using the controlled flux of PVC particles (Chritin and others, 1999). The sensor gives an estimation of the mass flux of snow $\left(\mathrm{g} \mathrm{m}^{-2} \mathrm{~s}^{-1}\right)$. The signal intensity and the 


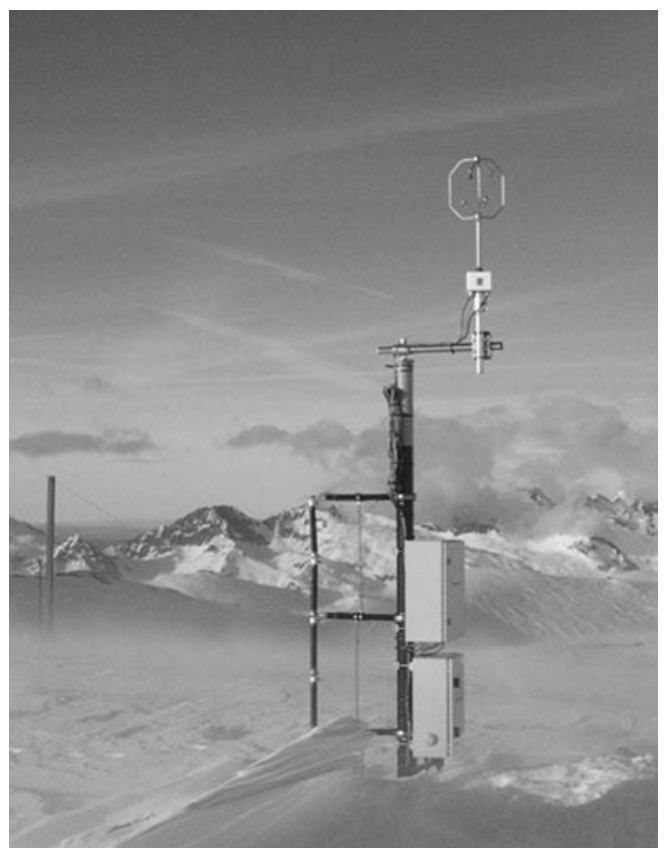

Fig. 4. FlowCapt with six vertical tubes in 2004.

momentum of snow grains are assumed to be related by a physical law, which is supported by laboratory experiments performed with PVC balls (Chritin and others, 1999). The estimated flux is computed using

$$
F_{\mathrm{d}}=A \times \text { Signal }^{2},
$$

where $F_{\mathrm{d}}$ denotes the flux data displayed by the sensor, and Signal the electrical voltage picked up by the data logger $(\mathrm{mV})$. The FlowCapt set-up at Col du Lac Blanc provided profiles of snow fluxes $0-180 \mathrm{~cm}$ above ground level.

It is thus possible to obtain an estimation of the transport rate with respect to the height above the snow surface. The use of concurrent wind-profile data made it possible to evaluate drift density data and therefore the product of settling velocity times Schmidt number.

For theoretical reasons, which are explained below, the six tubes were set up horizontally in 2008 (Fig. 5).

Snow Particle Counter. Since 2008 the drifting-snow flux has also been measured with the Snow Particle Counter (SPC-S7, Niigata Electric), which works on an optical method (Sato and Kimura, 1993). The diameter and the number of blowing-snow particles are detected by their shadows on photosensitive semiconductors. Electric pulse signals of snow particles passing through a sampling area are sent to an analysing logger. The SPC thereby detects particles $50-500 \mu \mathrm{m}$ in size, divides them into 32 classes and records the number of particles every $1 \mathrm{~s}$. Assuming spherical snow particles, the horizontal snow mass flux $q$ is calculated as (Sugiura and others, 1998)

$$
q=\sum q_{d}=\sum n_{\mathrm{d}} \frac{4}{3} \pi\left(\frac{d}{2}\right)^{3} \rho_{\mathrm{p}}
$$

where $q_{d}\left(\mathrm{~kg} \mathrm{~m}^{-2} \mathrm{~s}^{-1}\right.$ is the horizontal snow mass flux for the diameter $d(\mathrm{~m}), n_{\mathrm{d}}$ is the number flux of the drifting-snow particles and $\rho_{\mathrm{p}}$ is the density of the drifting-snow particles $\left(917 \mathrm{~kg} \mathrm{~m}^{-3}\right)$. It must be pointed out that the flux value is given for a small sampling area $\left(50 \mathrm{~mm}^{2}\right)$.

Butterfly net. Specific field measurements have been performed to obtain an estimation of snowdrift from
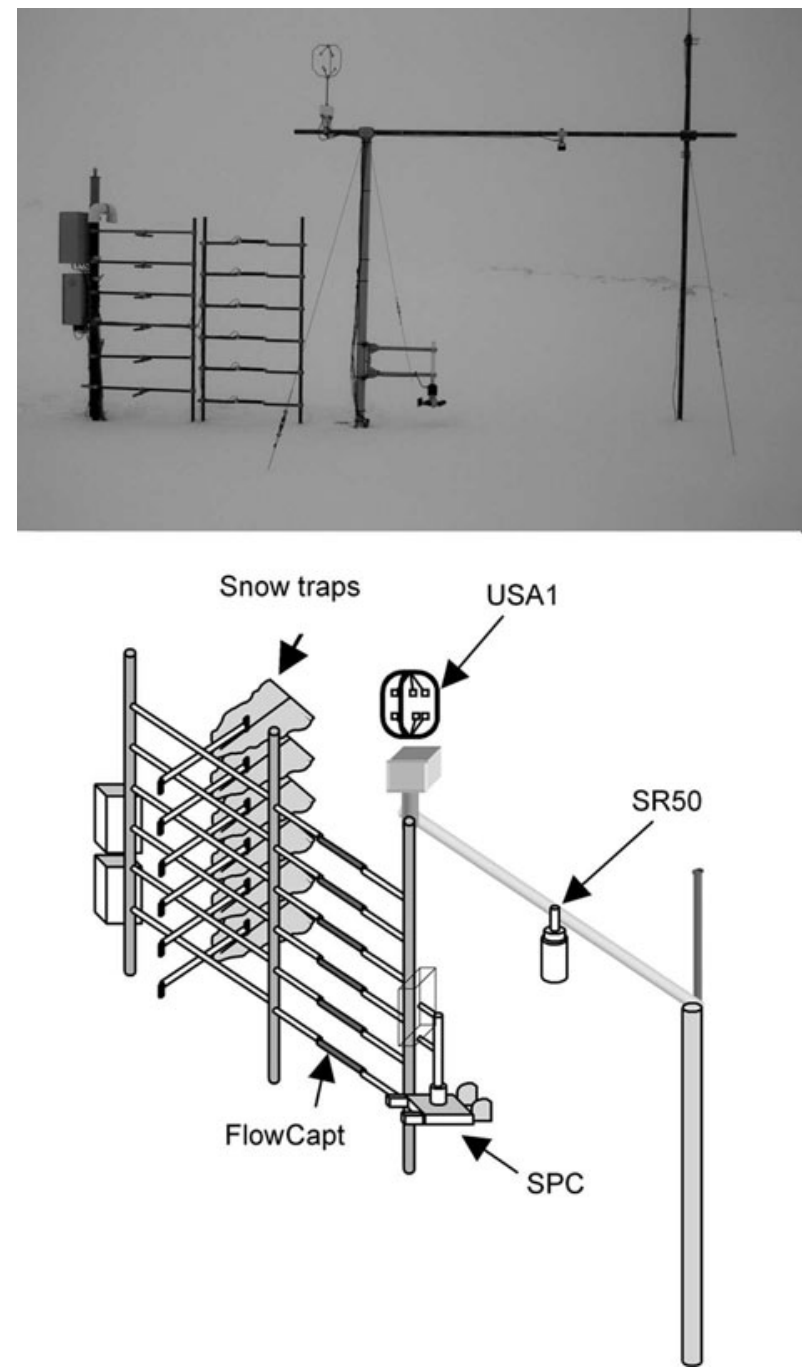

Fig. 5. Final configuration of the snowdrift sensors test bed at Col du Lac Blanc in 2008.

mechanical snow traps that could be compared with data recorded by FlowCapt and SPC (Fig. 6). The traps consisted of 'butterfly nets', i.e. a metallic frame with a nylon bag attached. The mixture of air and snow grains goes through the traps and, while the snow is collected in the bag, the air escapes through the pore. The cross-section is similar to that of FlowCapt, i.e. $0.007776 \mathrm{~m}^{2}$. Such snow collectors disturb the flow, and their efficiency depends on the aerodynamic design. Nonetheless, they are still the best reference and less expensive than SPC sensors, though they require the presence of experimenters under cold and windy conditions.

Field tests and intercomparison. Intercomparison tests with FlowCapt, SPC and snow-net collectors have already been done in the past. Font and others (2001) used the SPC to calibrate four different mechanical traps in a cold wind tunnel (Cryospheric Environment Simulator, Japan) with disintegrated snow. They showed that the net-type traps underestimate transport in low-transport conditions, but as transport increases, the difference tends to zero. Lehning and others (2002) presented the first evaluation of the accuracy of an acoustic sensor by comparing snow traps and acoustic sensors both in a cold wind tunnel (Jules Verne wind tunnel, France) and under natural conditions in the Alps. The results were disappointing: they confirmed preliminary results that acoustic sensors are only suitable 


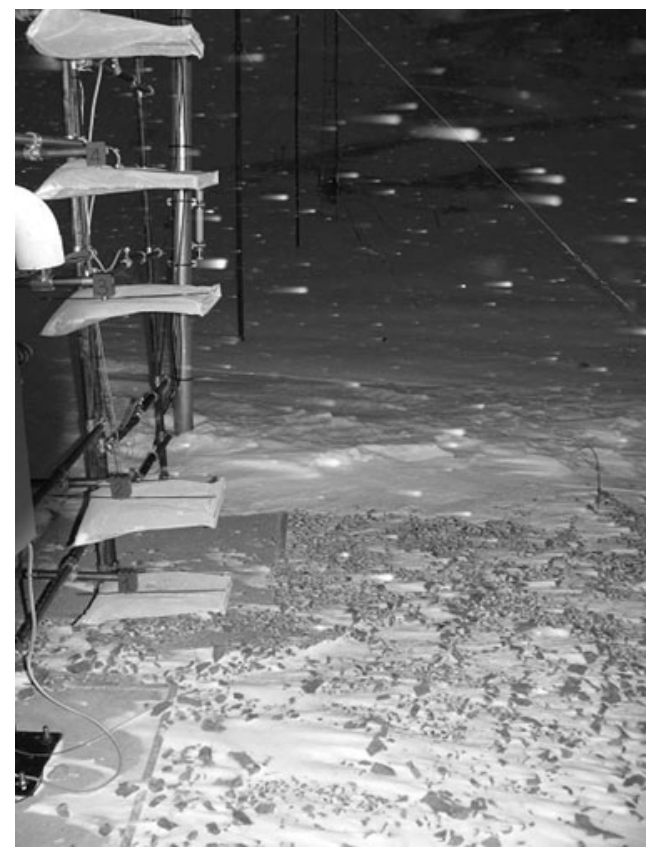

Fig. 6. Mechanical snow traps.

for giving qualitative or semi-quantitative results, as there are still some calibration issues to resolve. Savelyev and others (2006) deployed snow bags and a FlowCapt device and other instruments related to drifting-snow monitoring in Franklin Bay, Canada. They showed that FlowCapt overestimates snow mass flux as determined by snow bags by an order of magnitude. This is why we continue calibration at Col du Lac Blanc (Cierco and others, 2007). During some snowdrift events, each segment of FlowCapt was compared to mechanical snow traps whose cross-sections were designed to be exactly the same as the FlowCapt crosssections.

The shear velocity, $u *$, was estimated from one measurement point (ultrasonic anemometer $3.3 \mathrm{~m}$ high) assuming a logarithmic profile in the atmospheric boundary layer and Pomeroy's formula for $z_{0}$ (Equation (11)). In Figure 7, segment 1 is near the ground $(0.3 \mathrm{~m})$ and segment 3 is the highest $(0.9 \mathrm{~m})$ on which significant blowing snow is recorded. The correlation between FlowCapt and the snow bag is significant for a given segment (Fig. 7) and consequently for a given height. However, the behaviour of the sensor depends on the height: the higher FlowCapt is,

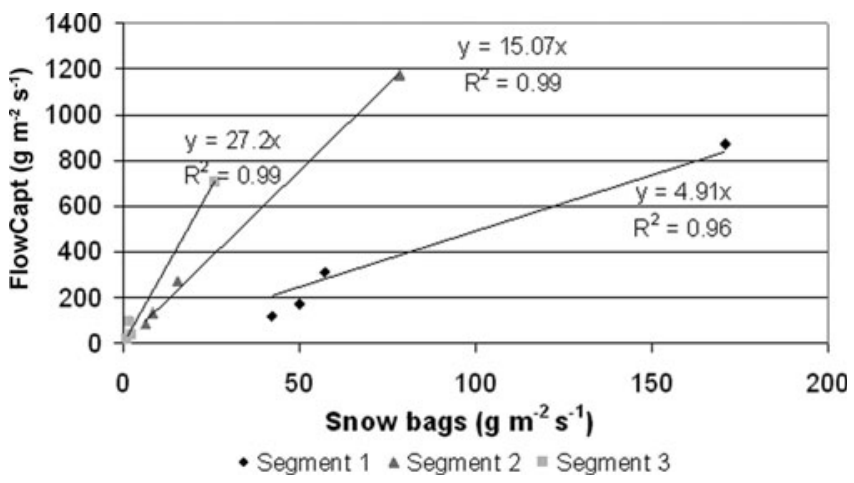

Fig. 7. Relation between the snow flux recorded on FlowCapt and measured by the mean of snow bags for different heights.

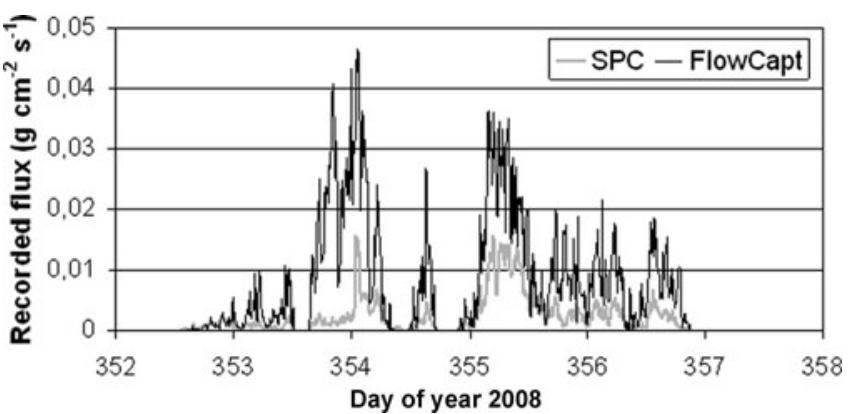

Fig. 8. Data from a prolonged drifting snow (17-22 December 2008): comparison between SPC and FlowCapt.

the greater is the slope of the linear regression line $(4.9$ for $0.15 \mathrm{~m}, 15.07$ for $0.45 \mathrm{~m}$ and 27.2 for $0.75 \mathrm{~m}$ ).

As the main difference for different heights was the particle horizontal velocity which is considered equal to the wind speed at the same height, all the data were re-treated considering this new parameter (Cierco and others, 2007). In this way, it was established that the poor treatment of particle velocity, which is not taken into account in the initial calibration curve, results in aberrations in the recorded data.

A correction algorithm based on statistical calibration of the sensor for rounded grains was proposed. The new calibration curve is

$$
F_{\mathrm{d}}=\frac{\text { Signal }^{2}}{B U^{4}}
$$

with $B=1.49$ for rounded grains

It should be noted that $F_{\mathrm{d}}$ varies with the inverse of the particle velocity to the fourth power, so that the acoustic sensor appears to be insufficiently accurate whatever the calibration may be (the value of $B$ depends on the particle type). In order to improve the calibration and as the velocity gradient is high near the ground, we set up the six tubes horizontally in 2008 (Fig. 5).

During winter 2008/09, the only year during which the SPC and FlowCapt were set up side by side, ten driftingsnow events were identified. For all the events (except when the SPC is buried under the snow cover), FlowCapt and the SPC give similar values for the occurrence of drifting snow (Fig. 8), but FlowCapt systematically overestimates snow mass flux as determined by snow bags (Fig. 10).

The particle size distribution cannot be measured at a given height since the snow depth changes, but event 5 is a representative sample of the encountered blowing-snow events during winter 2008/09. Generally the mode, which is the peak-frequency diameter, is centred around $80 \mu \mathrm{m}$ (Fig. 9a), but when we consider the frequency volume distribution, the peak-frequency diameter is centred around $200 \mu \mathrm{m}$ (Fig. 9b). The minimum diameter class seems to be underestimated, as there is no physical explanation for all particles having a diameter greater than $50 \mu \mathrm{m}$ during blowing snow; furthermore, particles with a diameter $<50 \mu \mathrm{m}$ were observed during blowing-snow events (Gordon and Taylor, 2009). However, the weight of such particles in the calculation of the horizontal snow mass flux is negligible. The maximum diameter class $(493 \mu \mathrm{m})$ includes all the larger particles, but, in this case, the weight of such particles in the calculation of the horizontal snow mass flux is important, and some underestimation of snow flux could 

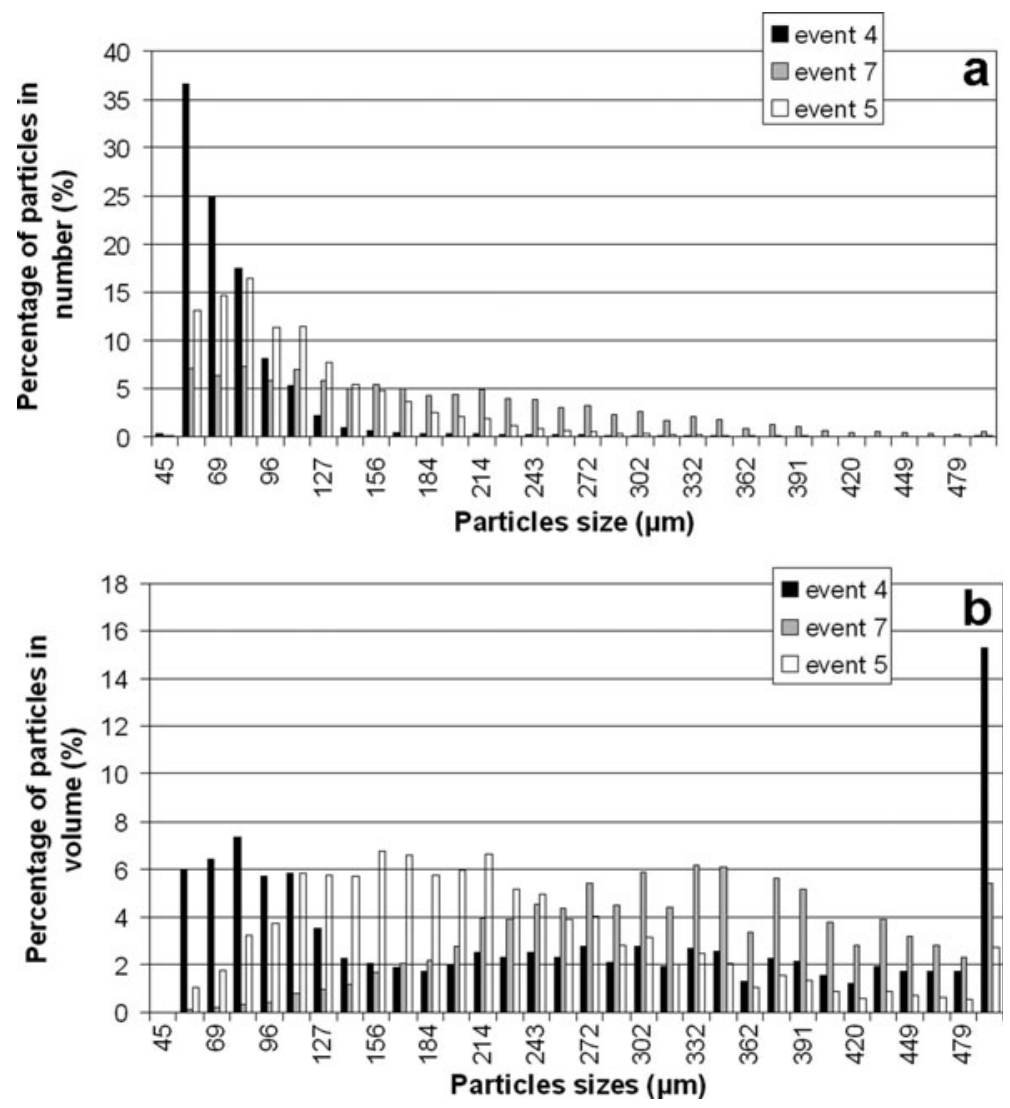

Fig. 9. Frequency distribution of drifting-snow particle diameter (a) and frequency volume distribution of drifting-snow particle diameter (b) (event 4: $V_{8.4 \mathrm{~m}}=5.8 \mathrm{~m} \mathrm{~s}^{-1}, \quad H_{\mathrm{SPC}}=0.2 \mathrm{~m}$, duration $940 \mathrm{~min}$; event 5: $V_{8.3 \mathrm{~m}}=10 \mathrm{~m} \mathrm{~s}^{-1}, H_{\mathrm{SPC}}=0.45 \mathrm{~m}$, duration $1750 \mathrm{~min}$; event 7 : $V_{8.6 \mathrm{~m}}=13 \mathrm{~m} \mathrm{~s}^{-1}, H_{\mathrm{SPC}}=0.28 \mathrm{~m}$, duration $700 \mathrm{~min}$ ).

appear. As noticed by Sugiura and others (1993), the frequency distribution becomes flatter with increasing wind (Fig. 9a, event 7) due to the increase in wind-borne particle diameter with $u_{*}$. Conversely, the frequency of smaller particles increased with decreasing wind (Fig. 9a, event 4). We also propose that the particle diameter is calculated from a projected area difference from an equivalent diameter based on volume for non-spherical diameter. Sato and Kimura (1993) have estimated this error theoretically for spheroid and square-pillar shapes. Nevertheless the SPC has been used extensively and is recognized to give accurate results. During winter 2008/09, we compared snow mass

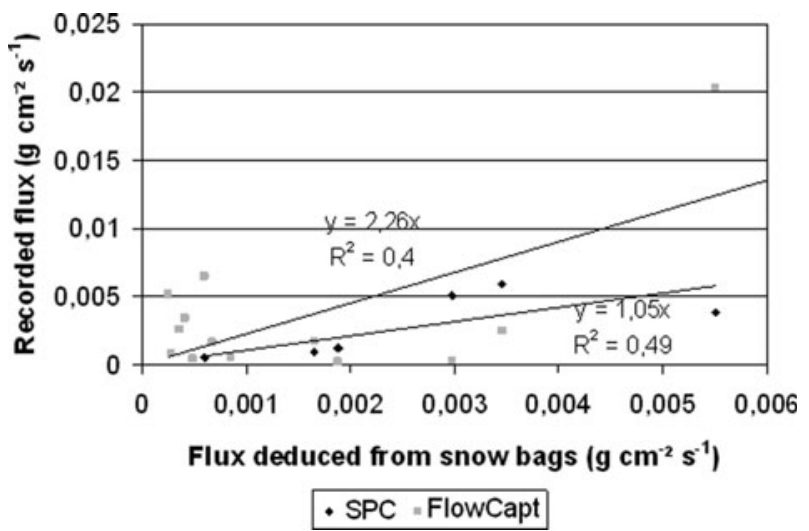

Fig. 10. Comparison between snow mass flux recorded by SPC and FlowCapt and deduced from snow bags. flux recorded by the SPC and FlowCapt and deduced from snow bags (Fig. 9b). It was shown that, for the given event (rounded grains), the SPC and snow bags show good agreement. We first compare snow mass flux recorded by the SPC and FlowCapt and then use the new calibration curve previously proposed (Equation (15)). The wind speed at the height of the FlowCapt tube is estimated from the $10 \mathrm{~m}$ tower with six anemometers. It can be seen that the new calibration affects the snow flux estimation (Fig. 11a and b); the slope of the linear regression line increases but is still very different from 1 , and data are more scattered, with a decreasing correlation coefficient $\left(R^{2}=0.26\right)$.

\subsection{Results}

\subsubsection{Determination of aerodynamics roughness}

The friction velocity is determined by a profile method using data from the $10 \mathrm{~m}$ tower with six anemometers. Generally, the near-surface distribution with height of time-averaged wind speed varies logarithmically.

$$
U(z)=\frac{u_{*}}{K} \ln \left(\frac{z}{z_{0}}\right)
$$

with $U$ the wind speed $\left(\mathrm{m} \mathrm{s}^{-1}\right), z(\mathrm{~m})$ the height above the snow cover, $K$ the von Kármán constant (usually taken to be $0.4)$ and $z_{0}$ the surface roughness (m), which is independent of the wind speed.

Thus, in a semi-log space, the friction velocity $u_{*}$ is proportional to the inverse of the slope of the straight line, and the aerodynamic roughness $z_{0}$ represents the intercept. The logarithmic profile is valid only in neutral conditions 
and for flat terrain. Due to the surrounding topography at Col du Lac Blanc, some deviation from this profile could occur. First we have tested that it is still approximately valid close to the surface at the measurement point. Generally, the eddy correlation method can also be applied using the ultrasonic anemometer, but this was not done since some problems occurred with the ultrasonic anemometer during the period of interest. However, comparison of the two methods (profile method and eddy correlation method) is at hand for other measurements at Col du Lac Blanc.

Snow transport alters the effective roughness of the bed by extracting momentum from the wind due to the necessary horizontal acceleration of drifting-snow particles. The resulting roughness measured by extrapolating the velocity profile outside the saltation layer shows a dependence on friction velocity. The wind modification during saltation is perceived by the flow as an increase in surface roughness due to the straight line extrapolations of the wind velocity on a log-linear plot from above the saltation layer to $u=0$ (Anderson and Haff, 1991; see Fig. 15). According to Owen (1964), the saltation layer acts like a solid roughness on the flow and leads to a roughness height proportional to the square of the friction velocity (Equation (11)). Pomeroy and Gray (1990) proposed a value of 0.1203 for $C_{0}$ for landbased snow cover. This is nearly an order of magnitude greater than Tabler's (1980) $\left(C_{0}=0.02648\right)$ and Schmidt's (1990) values for lake ice-based snow covers.

Andreas and others (2004) develop a new parameterization for $z_{0}$ as function of the friction velocity over snow.

$z_{0}^{\prime}=\frac{0.135 \nu}{u_{*}}+0.035 \frac{u_{*}^{2}}{2 g}\left\{1+A \exp \left[-\left(\frac{u_{*}-0.18}{0.1}\right)^{2}\right]\right\}$

In this case, $\frac{0.135 \nu}{u_{*}}$ models the aerodynamic smooth regime, $0.035 \frac{u_{*}^{2}}{2 g}$ models the saltation regime and the last term reflects the roughness of the surface as $A$ depends on the tested site.

The present study explores how the measured $z_{0}$ correlates with values of $u_{*}$ during a drifting-snow event at Col du Lac Blanc. There is a limited number of velocity data periods that occur during thermally neutral periods. In the following, results where $R^{2}<0.9$ and potential temperature difference is $>1$ were rejected.

The following observations can be made:

For the same value of friction velocity, roughness values are dispersed, leading to a low coefficient of determination.

Without drifting snow, the surface roughness could depend on the wind direction, because the topography of the two fetches is different (Fig. 12a).

The proportionality of $z_{0}^{\prime}$ to the square of the friction velocity seems to be confirmed, but once again the coefficient of determination is rather low.

Given the formation of aeolian features (e.g. sastrugi), the roughness height could be greater after the storm (Fig. 12c). The change in the surface roughness during the snowstorm could perhaps explain the rather low coefficient of determination. There are also probably some topographic effects due to up- and downwind slopes. The value of $C_{0}$ depends on the snowdrift events (Fig. 12b-d) for the same site. There is a two orders of magnitude difference between
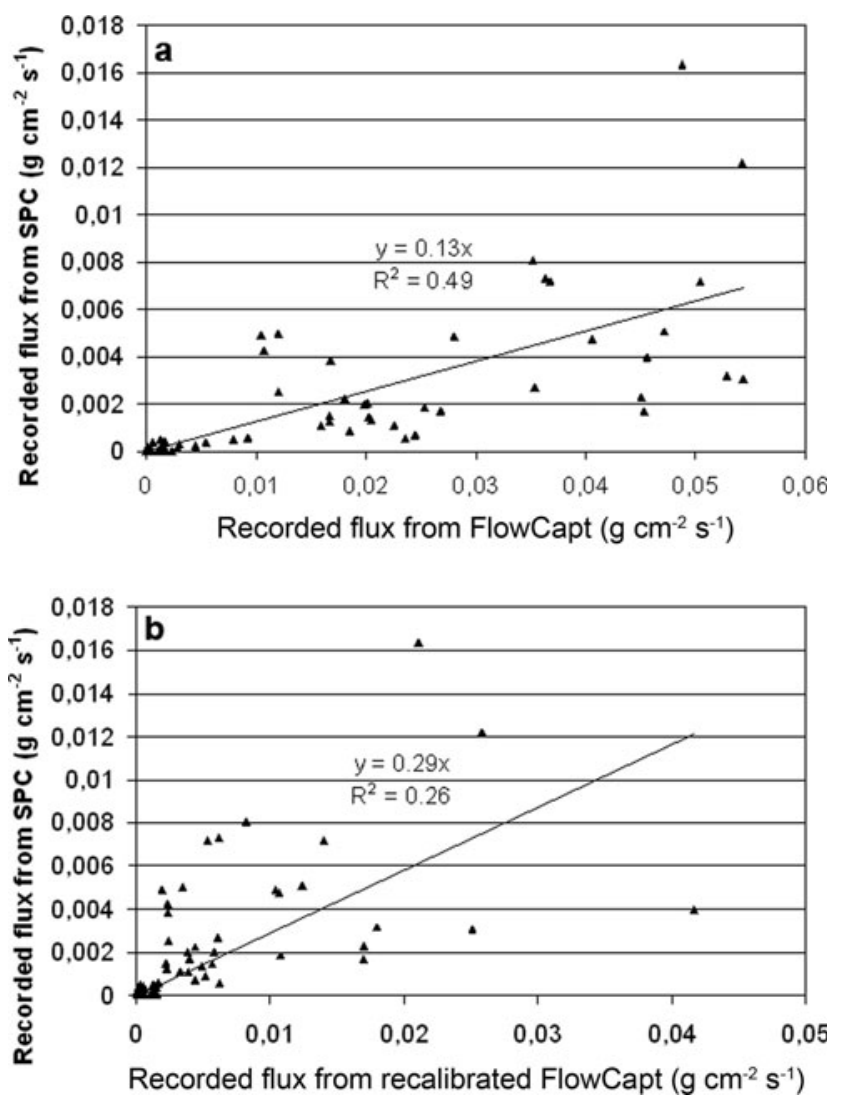

Fig. 11. Comparison between snow mass flux recorded by SPC and FlowCapt (a) and by SPC and recalibrated FlowCapt (b).

the different values. Except for the smallest value (Fig. 12d), the range corresponds to values observed by Tabler (1980), Pomeroy and Gray (1990) and Andreas and others (2004).

As the apparent increase of roughness is related to the exchange of momentum between wind and snow particles in the saltation layer, the wide variation of $C_{0}$ is not surprising: the roughness must be related to the snow flux in the saltation layer, so the threshold friction velocity must also be taken into account (Equation (11)).

For an accurate estimation of the input parameters for $\mathrm{NEMO}$, a semi-empirical model is not sufficient because the coefficient $C_{0}$ depends on the drifting-snow event and varies by at least a factor of 1-100. It is important to note that an error in estimating $z_{0}$ leads to an error in estimating $u_{*}$ when using only one wind measurement point.

\subsubsection{Determination of $\sigma_{s} U_{F}$}

In steady state, the transport of snow particles is governed by a balance between gravitational settling and turbulent diffusion leading to Equation (4) for the concentration profile. The implicit assumption is that the particle size distribution does not change significantly with height. Velocity and concentration profiles can be used to calculate the exponent of the equation. As a first step, all data from the 2004/05 winter season for blowing-snow events involving rounded grains had to be reprocessed using the new calibration curve (Equation (15)). Such events have been isolated using Crocus (Brun and others, 1992), which simulated the different physical and mass processes into the snow cover and its complete stratigraphy. The value of $u_{*}$ is calculated from a single wind measurement point at $3.3 \mathrm{~m}$, using the semi-empirical formulae for $z_{0}$ with 

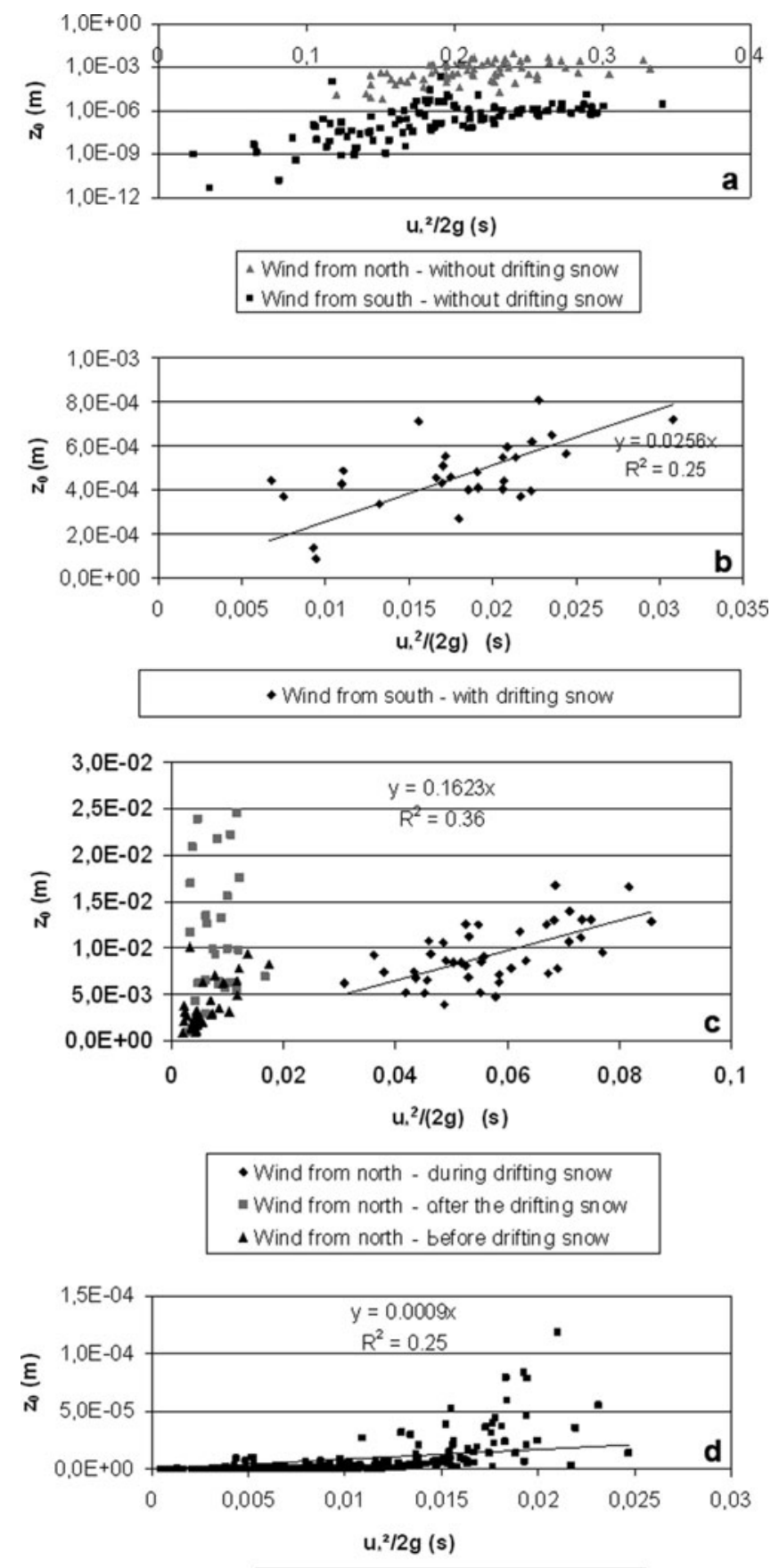

- Wind from north - with drifting snow

Fig. 12. Roughness height plotted against friction velocity.

$C_{0}=0.1203$. This leads to the curve relating $\sigma_{\mathrm{s}} U_{\mathrm{F}}$ and $u_{*}$ (Fig. 13)

It could be concluded from Figure 13 that the use of the empirical formula obtained from Antarctic data seems to underestimate $\sigma_{\mathrm{s}} U_{\mathrm{F}}$ in the French Alps. But in fact it was seen in section 3.1.2 that FlowCapt was not deemed suitable for research applications and that an error in estimating $z_{0}$ leads to an error in estimating $u_{*}$ when using only one wind measurement point. This is why we returned to the traditional robust mechanical traps coupled with the $10 \mathrm{~m}$ mast to determine $u_{*}$ and $z_{0}$. Of course, it would be better to use several SPCs as done by Mann and others (2000) or Gordon and Taylor (2009), but only one sensor was available on our experimental site.

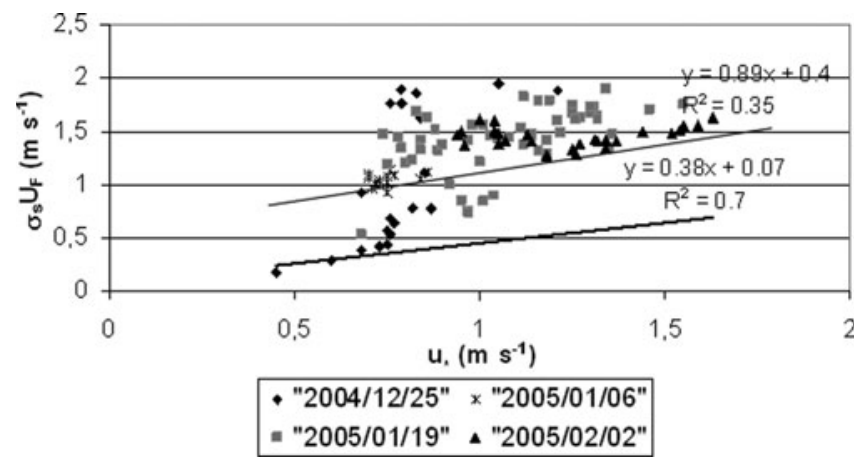

Fig.13. Change in product $\sigma_{\mathrm{S}} U_{\mathrm{F}}$ as a function of $u_{*}$ at Col du Lac Blanc from FlowCapt and one wind measurement point (gray line represents relationship obtained with data from Antarctica). Dates: year/month/day.

Contrary to what we concluded previously from FlowCapt data processing, the relation between $\sigma_{\mathrm{s}} U_{\mathrm{F}}$ and $u_{*}$ slightly differs from those obtained in Antarctica: the regression obtained in Antarctica still lies in the scatter of the data. If the value of $u *$ is calculated from a single wind measurement point at $8.8 \mathrm{~m}$, using the semi-empirical formulae for $z_{0}$ with $C_{0}=0.1203$, points are shifted to the right in Figure 14, but the slope of the regression line does not differ significantly. The empirical formula obtained from Antarctic data for $\sigma_{\mathrm{s}} U_{\mathrm{F}}$ can be used at Col du Lac Blanc. Nevertheless, mechanical measurements for higher friction velocity must be conducted to confirm this trend.

It is also interesting to compare the data processing we did in 1996, with the 1200 usable data from Mellor and Radok (1960) and Budd and others (1966) obtained in Antarctica, with more recent experimental data obtained by Mann and others (2000) or Gordon and Taylor (2009). Mann and others (2000) measured concentration profiles using six particle counters at the Halley research base in Antarctica; they found that the settling velocity (assuming that the Schmidt number is equal to 1 ) increases with friction velocity $\sigma_{\mathrm{s}} U_{\mathrm{F}}=0.4 u_{*}$ up to $u_{*}=0.375 \mathrm{~m} \mathrm{~s}^{-1}$, after which it is approximately constant. With two similar particle counters, Gordon and Taylor (2009) showed a slightly higher settling velocity, with a continuous increase with friction velocity (even for $u_{*}>0.375 \mathrm{~m} \mathrm{~s}^{-1}$ ), at Franklin Bay, Canada. These are very similar to our own results. As pointed out by Gordon and Taylor (2009), the continuous increases of $\sigma_{\mathrm{s}} U_{\mathrm{F}}$ with $u_{*}$ indicate that larger particles were available in experiments done by Mellor and Radok (1960), Budd and others (1966) and Gordon and Taylor (2009). However, some authors consider that the Schmidt number is lower than 1. Naaim and Martinez (1995) obtained a value of 0.5 in a wind tunnel for PVC particles. Listen and others (1994) used a value of 0.5 in a computational blowing-snow model referring to Reynolds' work (1976) for planar flows. The same orders of magnitude are found by Sanjeev and Bombardelli (2009) when they assess diverse turbulence closure in the simulation of dilute sediment-laden open-channel flows.

\subsubsection{Determination of the drifting-snow concentration profile}

Combining results from measurements on a snow-covered plain and theory, Pomeroy and Gray (1993) proposed Equation (10) for determining $C_{\text {salt, }}$ the mean drift density of saltating snow $\left(\mathrm{kg} \mathrm{m}^{-3}\right) . C_{\text {salt }}$ is also the lower boundary 


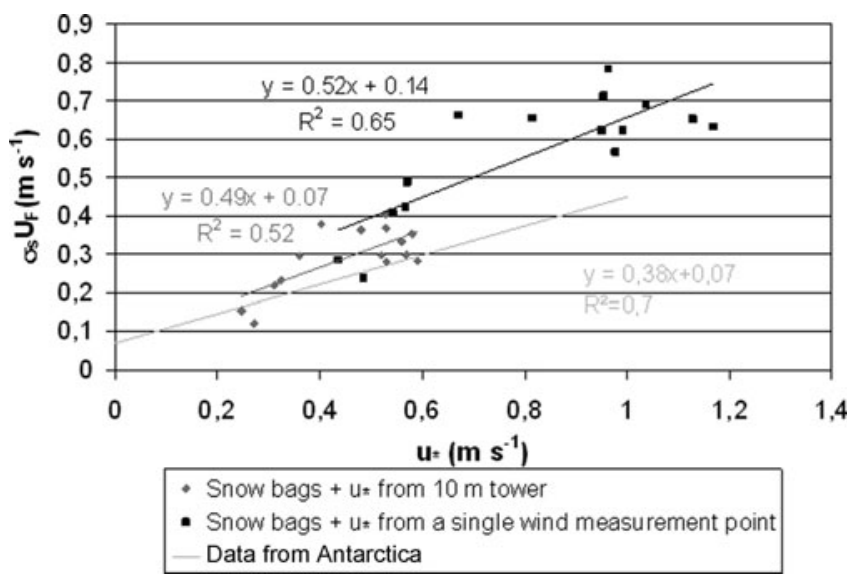

Fig. 14. Change in product $\sigma_{\mathrm{s}} U_{\mathrm{F}}$ as a function of $u_{*}$ at Col du Lac Blanc (snow-bag measurements taken in March 2008: 75 data available; rounded grains).

condition of Equation (5) for the suspension model. Following Pomeroy and Gray, the height $h_{*}$ that delineates the saltation and suspension layers can be approximated by

$$
h_{*}=0.08436 u_{*}^{1.27} \text {. }
$$

This value was found by extrapolating the modelled suspension mass concentration towards the saltation layer until they approximate the mean drift density $C_{\text {salt }}$. For $u_{*}<1.05 \mathrm{~m} \mathrm{~s}^{-1}$, this leads to suspension drift density greater than those calculated with the lower boundary condition equal to the height of the saltation layer (Equation (9)). Equation (4) becomes

$$
C(z)=\frac{2 \times 0.68}{2.8 \times 1.6} \frac{\rho}{u_{*}}\left(1-\frac{u_{* t}^{2}}{u_{*}^{2}}\right)\left(\frac{z}{0.08436 u_{*}^{1.27}}\right)^{-\frac{\sigma_{\mathrm{S}} U_{\mathrm{F}}}{K u_{*}}} .
$$

Using Equation (19), snowdrift events from 4-5 March 2008 and 27 February 2009 have been simulated. In both cases, the value of $\sigma_{\mathrm{S}} U_{\mathrm{F}}$ used comes from the linear regression of the data obtained with snow traps (Fig. 14) and $u_{*}$ was determined from a profile method thanks to the $10 \mathrm{~m}$ tower with six anemometers. Data for height $<10 \mathrm{~cm}$ were rejected because near the saltation layer (in the so-called modified saltation layer) particles are in transition from saltation to

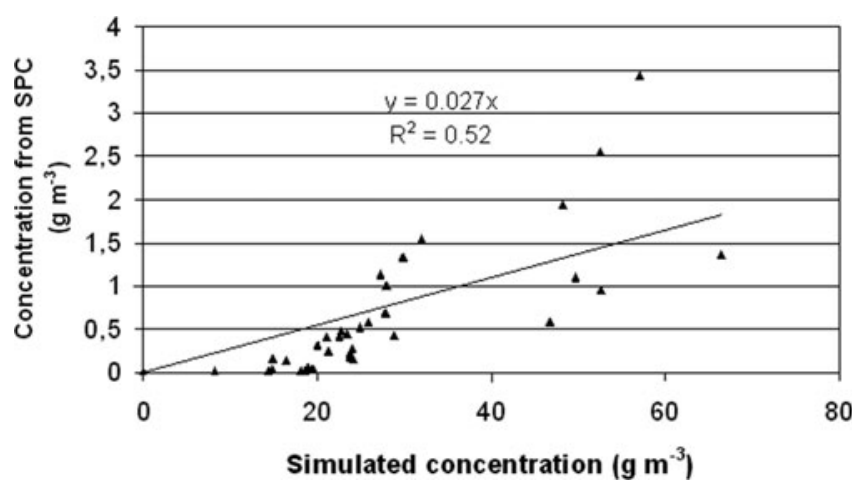

Fig. 15. Snowdrift concentration obtained by SPC on 27 February 2009 as function of simulated concentration obtained using Pomeroy and Gray's semi-empirical formulae for saltation layer coupled with theoretical approach for the diffusion layer (Equation (19)).

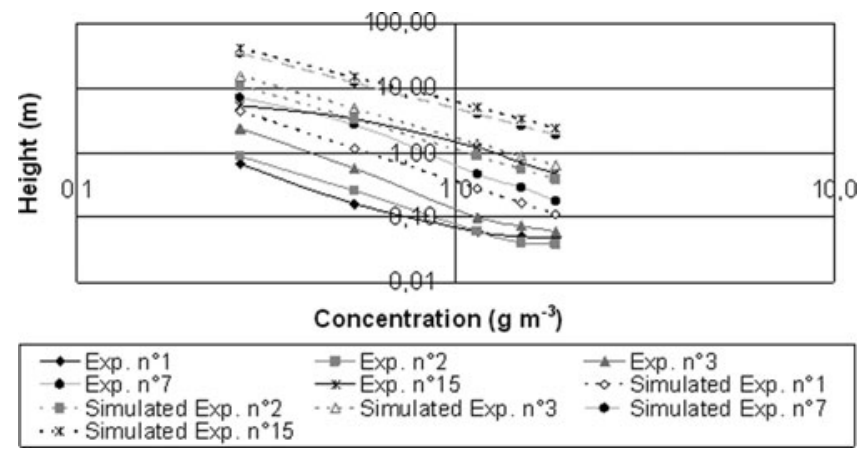

Fig. 16. Snowdrift concentration profiles obtained by snow traps (solid lines) on 4 March 2008 and by Pomeroy's semi-empirical formulae for saltation layer coupled with theoretical approach for the diffusion layer (dotted lines) (Equation (19)).

suspension and probably have not achieved full horizontal wind velocity.

It can be seen from Figures 15-17 that the semi-empirical formulation proposed by Pomeroy and Gray (1993) overestimates the profile by one order of magnitude. Our comments on this are:

1. Results concerning aerodynamic roughness and concentration are in agreement: as the apparent increase of roughness is related to the exchange of momentum between wind and snow particles in the saltation layer, less snow flux leads to a smaller aerodynamic roughness.

2. Works of Pomeroy and Gray's have been established for a steady state and a fully developed flow, which could imply a fetch with a constant friction velocity and snow supply from 150 to $300 \mathrm{~m}$ for the lowest $0.3 \mathrm{~m}$ of the atmospheric boundary layer for a snowdrift event (Takeuchi, 1980). Such conditions are rarely or never encountered in an Alpine context. Therefore the simulated concentration must be considered a maximum value. This was precisely the idea we developed in the numerical model NEMO, in which the inertia of snow erosion and deposition is taken into account by means of

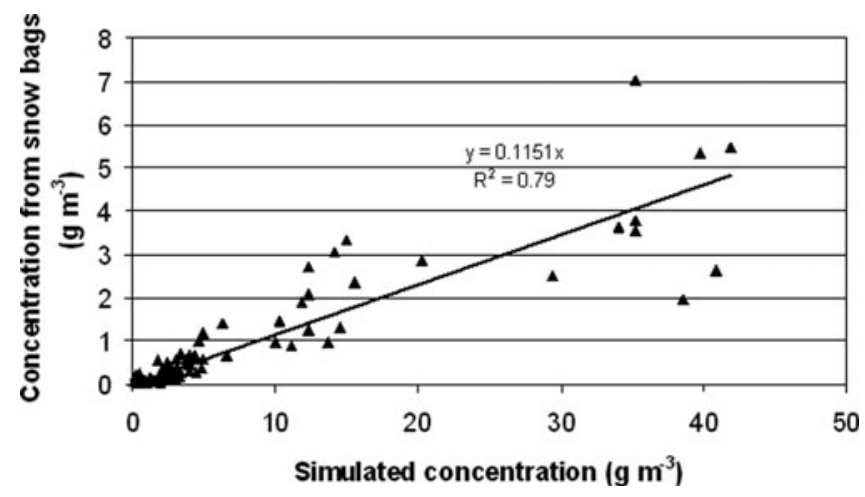

Fig. 17. Snowdrift concentration obtained by snow traps on 4 March 2008 as function of simulated concentration obtained using Pomeroy and Gray's semi-empirical formulae for saltation layer coupled with theoretical approach for the diffusion layer (Equation (19)). 
erosion and deposition flux: $C_{\text {salt }}$ (Equation (10)) is considered as the maximum snow concentration in the saltation layer (Naaim and others, 1998). Logically, input concentration profiles of such a model must also take into account inertia of snow erosion and deposition upwind of the zone of interest. The simulated profile (Equation (19)) cannot apply as a concentration profile boundary condition: the measured concentration profile must be the upwind boundary condition, or at least a long fetch distance must be simulated upwind of the zone of interest.

\section{CONCLUSION AND FURTHER DEVELOPMENTS}

Accurate input parameters cannot be omitted when studying the ability of a numerical model to reproduce field experiments. In the case of NEMO, the use of empirical formulae is not enough and their validity has been tested by improving instrumentation dedicated to blowing-snow setup at Col du Lac Blanc.

It was shown for the studied drifting-snow events that (1) the square of the friction velocity seems to be confirmed, but with a varying constant depending on the snowdrift event and a poor coefficient of determination; (2) values of $\sigma_{\mathrm{S}} U_{\mathrm{F}}$ are relatively well approximated by empirical formulae obtained from Antarctica data; and (3) snowdrift concentration profiles obtained by Pomeroy's semi-empirical formulae for the saltation layer coupled with a theoretical approach for the diffusion layer lead to an overestimation of the concentration profiles.

However, few accurate concentration profiles have been obtained because such data require the presence of an experimenter; at the present time, data from FlowCapt are not sufficiently accurate for research purposes. The settingup of a second SPC in the near future will allow us to increase the dataset and perhaps better investigate the relation between aerodynamic roughness and snow flux and also the relation between the friction velocity and $\sigma_{\mathrm{s}} U_{\mathrm{F}}$. The Schmidt number is a key factor for predicting sediment transport in suspension. Thus the next step will be to combine concentration profiles using particle counters and direct determination of particle vertical velocity by a camera system (as used by Gordon and Taylor, 2009) to better investigate the value of the Schmidt number.

\section{ACKNOWLEDGEMENTS}

We thank F.-X. Cierco, F. Perault, F. Ousset, X. Ravanat and $R$. Beguin for support with the field measurements.

\section{REFERENCES}

Anderson, R.S. and P.K. Haff. 1991. Wind modification and bed response during saltation of sand in air. In Barndorff-Nielsen, O.E. and B.B. Willetts, eds. Aeolian grain transport: mechanics. Vienna, etc., Springer, 21-52. (Acta Mechanica. Supplementum 1.)

Andreas, E.L., R.E. Jordan, P.S. Guest, O.G. Persson, A.A. Grachev and C.W. Fairall. 2004. Roughness lengths over snow. In Proceedings of the 18th Conference on Hydrology of the American Meteorological Society, 11-15 January 2004, Seattle, WA. Washington, DC, American Meteorological Society. CD-ROM JP4.31.
Bintanja, R., H. Lilienthal and H. Tüg. 2001. Observations of snowdrift over Antarctic snow and blue-ice surfaces. Ann. Glaciol., 32, 168-174.

Brun, E., P. David, M. Sudul and G. Brunot. 1992. A numerical model to simulate snow-cover stratigraphy for operational avalanche forecasting. J. Glaciol., 38(128), 13-22.

Budd, W.F., W.R.J. Dingle and U. Radok. 1966. The Byrd snow drift project: outline and basic results. In Rubin, M.J., ed. Studies in Antarctic meteorology. Washington, DC, American Geophysical Union, 71-134. (Antarctic Research Series 9.)

Chritin, V., R. Bolognesi and H. Gubler. 1999. FlowCapt: a new acoustic sensor to measure snowdrift and wind velocity for avalanche forecasting. Cold Reg. Sci. Technol., 30(1-3), 125-133.

Cierco, F.-X., F. Naaim-Bouvet and H. Bellot. 2007. Acoustic sensors for snowdrift measurements: how should they be used for research purposes? Cold Reg. Sci. Technol., 49(1), 74-87.

Doorschot, J., N. Raderschall and M. Lehning. 2001. Measurements and one-dimensional model calculations of snow transport over a mountain ridge. Ann. Glaciol., 32, 153-158.

Doorschot, J.J.J., M. Lehning and A. Vrouwe. 2004. Field measurements of snow-drift threshold and mass fluxes, and related model simulations. Bound.-Layer Meteorol., 113(3), 347-368.

Font, D., F. Naaim-Bouvet and M. Roussel. 1998. Drifting-snow acoustic detector: experimental tests in La Molina, Spanish Pyrenees. Ann. Glaciol., 26, 221-224.

Font, D., T. Sato, K. Kosugi, A. Sato and J.M. Vilaplana. 2001. Massflux measurements in a cold wind tunnel: comparison of the mechanical traps with a snow-particle counter. Ann. Glaciol., 32, 121-124.

Gauer, P. 1998. Blowing and drifting snow in Alpine terrain: numerical simulation and related field measurements. Ann. Glaciol., 26, 174-178.

Gordon, M. and P.A. Taylor. 2009. Measurements of blowing snow, Part I: particle shape, size distribution, velocity, and number flux at Churchill, Manitoba, Canada. Cold Reg. Sci. Technol., 55(1), 63-74.

Jha, S.K. and F.A. Bombardelli. 2009. Two-phase modeling of turbulence in dilute sediment-laden, open-channel flows. Environ. Fluid Mech., 9(2), 237-266.

Lehning, M. and 8 others. 2002. Snow drift: acoustic sensors for avalanche warning and research. Natur. Hazards Earth Syst. Sci. (NHESS), 2(3/4), 121-128.

Liston, G.E., R.L. Brown and J.D. Dent. 1993. A two-dimensional computational model of turbulent atmospheric surface flows with drifting snow. Ann. Glaciol., 18, 281-286.

Mann, G.W., P.S. Anderson and S.D. Mobbs. 2000. Profile measurements of blowing snow at Halley, Antarctica. J. Geophys. Res., 105(D19), 24,491-24,508.

Mellor, M. and G. Fellers. 1986. Concentration and flux of windblown snow. CRREL Spec. Rep. 86-11.

Mellor, M. and U. Radok. 1960. Some properties of drifting snow. In Antarctic meteorology: proceedings of the symposium held in Melbourne, Australia, February 1959. Oxford, etc., Pergamon Press, 333-346.

Michaux, J.L., F. Naaim-Bouvet and M. Naaim. 2001. Drifting-snow studies over an instrumented mountainous site: II. Measurements and numerical model at small scale. Ann. Glaciol., 32, 175-181.

Naaim, M. and H. Martinez. 1995. Experimental and theoretical determination of concentration profiles and influence of particle characteristics in blowing snow. Surv. Geophys., 16(5-6), 695-710.

Naaim, M., F. Naaim-Bouvet and H. Martinez. 1998. Numerical simulation of drifting snow: erosion and deposition models. Ann. Glaciol., 26, 191-196.

Naaim-Bouvet, F., M. Naaim and H. Martinez. 1996. Profils de concentration de la neige soufflée: théorie, résolution numérique et validation expérimentale in situ. Houille Blanche, 51(5), $53-57$. 
Naaim-Bouvet, F., Y. Durand, J.-L. Michaux, G. Guyomarc'h, M. Naaim and L. Merindol. 2000. Numerical experiments of wind transport over a mountainous instrumented site at small, medium and large scales. In Proceedings of the International Snow Science Workshop 2000, 2-6 October 2000, Big Sky, Montana, USA. Bozeman, MT, American Avalanche Association, 302-308.

Owen, P.R. 1964. Saltation of uniform grains in air. J. Fluid Mech., 20(2), 225-242.

Pomeroy, J.W. and D.M. Gray. 1990. Saltation of snow. Water Resour. Res., 26(7), 1583-1594.

Pomeroy, J.W. and Gray, D.M. 1993. The Prairie Blowing Snow Model: characteristics, validation, operation. J. Hydrol., 144, 165-192.

Reynolds, A.J. 1976. The variation of turbulent Prandtl and Schmidt numbers in wakes and jets. Int. J. Heat Mass Transfer, 19(7), 7757-7764.

Sato, T., T. Kimura, T. Ishimaru and T. Maruyama. 1993. Field test of a new snow-particle counter (SPC) system. Ann. Glaciol., 18, 149-154.
Savelyev, S.A., M. Gordon, J. Hanesiak, T. Papakyriakou and P.A. Taylor. 2006. Blowing snow studies in the Canadian Arctic Shelf Exchange Study, 2003-04. Hydrol. Process., 20(4), 817-827.

Schmidt, R.A. 1986. Transport rate of drifting snow and the mean wind speed profile. Bound.-Layer Meteorol., 34(3), 13-241.

Sugiura, K., K. Nishimura, N. Maeno and T. Kimura. 1998. Measurements of snow mass flux and transport rate at different particle diameters in drifting snow. Cold Reg. Sci. Technol., 27(2), 83-89.

Sundsbø, P.-A. 1997. Numerical modeling and simulation of snow accumulaton around porous fences. In Proceedings of the International Snow Science Workshop, 6-11 October 1996, Banff, Alberta, Canada. Revelstoke, B.C., Canadian Avalanche Association, 135-39.

Tabler, R.D. 1980. Self-similarity of wind profiles in blowing snow allows outdoor modeling. J. Glaciol., 26(94), 421-434.

Takeuchi, M. 1980. Vertical profile and horizontal increase of driftsnow transport. J. Glaciol., 26(94), 481-492. 